\title{
Public health response to ultra-processed food and drinks
}

\author{
Growing evidence confirms a link between consumption of ultra-processed food and drinks and \\ non-communicable diseases. Jean Adams and colleagues explore the implications for public \\ health action
}

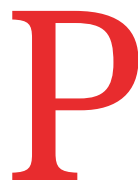

eople have used food processing to make food safe, palatable, and longer lasting since prehistoric times. ${ }^{1}$ Common modern food processing to achieve similar safety, palatability, and preservation goals includes pasteurisation of milk to reduce harmful microbes, milling of wheat to remove indigestible components, and canning fruit to increase its shelf life. However, in the past 100 years industrial techniques have been increasingly used to produce novel ultra-processed food and drink products.

Ultra-processed foods (a term which we use to include ultra-processed drinks in this article) tend to be highly palatable, convenient, shelf stable, and affordable, and are often marketed in ways that appeal to children. ${ }^{23}$ These characteristics may explain why, in high income and, increasingly, in middle-income countries, ultra-processed foods consistently account for more than $50 \%$ of dietary energy. ${ }^{4-6}$ However, evidence is growing that consumption of ultra-processed foods

\section{KEY MESSAGES}

- Ultra-processed food and drinks are products that are formulated from ingredients resulting from industrial processes

- Growing evidence associates greater consumption of ultra-processed foods with increased risk of non-communicable diseases

- Public health efforts should focus on wider determinants of consumption rather than selected nutrients or individual behaviours

- Structural interventions are required to increase access to convenient, palatable, and affordable minimally processed foods and dishes

- Reducing consumption will require simultaneous changes to supply and demand at local, national, and transnational levels is associated with increased risk of noncommunicable disease, presenting a public health challenge.

Several definitions and classifications of food processing exist, but in this article we use the Nova system (table 1). Despite some debate, ${ }^{89}$ Nova is emerging as the most conceptually coherent, operationally useful, and widely used in dietary public health research and policy. ${ }^{10}$

\section{Global changes in eating patterns}

Consumption of ultra-processed foods varies globally. In 2016, $271 \mathrm{~kg}$ of ultraprocessed foods were sold per capita in the North America and Australasia region compared with only $52 \mathrm{~kg}$ per capita in Africa. ${ }^{11}$ However, whereas sales were falling or stagnant in the regions with the highest consumption (Western Europe and North America and Australasia) sales of ultra-processed foods increased in all other regions in 2002-16-by a minimum of around 20\% in the Latin and Caribbean region to a maximum of around $90 \%$ in South and South East Asia. ${ }^{11}$ Studies in high income countries have reported an inverse association between consumption of ultra-processed foods and markers of socioeconomic position, ${ }^{12-14}$ but the reverse has been reported elsewhere. ${ }^{15}$ This probably reflects international differences in the affordability of ultra-processed foods. ${ }^{5}$

Many companies producing ultraprocessed foods have a global presence, ${ }^{16}$ and as market saturation occurs in higher income countries, there is evidence of "problem shifting" to lower income countries, which have become a growth market. For example, it has been estimated that Coca-Cola, which makes at least three quarters of its global sales from ultraprocessed drinks, ${ }^{17}$ invested more than $\$ 1 \mathrm{bn}(€ 0.8 \mathrm{bn}$; €0.9bn) a year in each of China, Brazil, Mexico, and Africa in the early 2010s. ${ }^{18}$

\section{Non-communicable disease risk}

Evidence is growing that greater consumption of ultra-processed foods is associated with increased risk of obesity and non-communicable diseases. For example, a longitudinal analysis of country level data from 2002 to 2016 found a positive association between sales of ultra-processed foods and mean body mass index (BMI) in men, and between ultra-processed drinks sales and mean BMI in both men and women. ${ }^{11}$ This is consistent with the findings of a recent randomised controlled trial of unrestricted ultra-processed versus unprocessed diets (matched for total energy, macronutrients, sugar, salt, and fibre) where participants randomised to the ultra-processed diet consumed an average of $508 \mathrm{kcal}$ more a day than those on the unprocessed diet and gained a mean of $0.9 \mathrm{~kg}$ over two weeks. ${ }^{19}$ Despite attempts to match on energy density, ultra-processed diets had a higher energy density indicating this may be an important mechanism of their effects on health.

Several prospective cohort studies have also reported associations between ultra-processed foods consumption and non-communicable disease outcomes. ${ }^{20}$ ${ }^{21}$ The largely consistent signal from these different study designs using different definitions of both exposure and outcome strengthens the claim that that greater consumption of ultra-processed foods is associated with increased risk of noncommunicable disease.

One harmful aspect of ultra-processed foods may be their nutritional profile. These products tend to be higher in energy density, free sugars, sodium, and saturated fats than less processed alternatives. ${ }^{22}$ Furthermore, positive associations have been reported between the percentage of total dietary energy from ultra-processed foods and higher intake of free sugars, saturated fats, and sodium; inverse associations are reported with consumption of fibre and fruit and vegetables. ${ }^{23}$ It has also been proposed that ultra-processing is itself harmful to health.

\section{Factors encouraging overconsumption}

Ultra-processed foods and drinks are less satiating than less processed alternatives, 


\begin{tabular}{|c|c|c|c|}
\hline Group & Name & Definition & Example products \\
\hline 1 & $\begin{array}{l}\text { Unprocessed or } \\
\text { minimally } \\
\text { processed foods }\end{array}$ & $\begin{array}{l}\text { Edible parts of plants or animals and fungi, algae, and water; or these } \\
\text { foods altered by processes such as removing inedible or unwanted } \\
\text { parts, drying, crushing, grinding, fractioning, filtering, roasting, boiling, } \\
\text { pasteurisation, refrigeration, freezing, placing in containers, vacuum } \\
\text { packaging, or non-alcoholic fermentation }\end{array}$ & $\begin{array}{l}\text { Fresh, squeezed, chilled, frozen, or dried fruits and vegetables, in- } \\
\text { cluding pulses; grains, grits, flakes, or flour; meat, poultry, fish, and } \\
\text { seafood; couscous and polenta; tree and ground nuts and other oil } \\
\text { seeds without added salt or sugar; spices and herbs; plain yoghurt; } \\
\text { tea and coffee }\end{array}$ \\
\hline 2 & $\begin{array}{l}\text { Processed culinary } \\
\text { ingredients }\end{array}$ & $\begin{array}{l}\text { Substances obtained directly from group } 1 \text { foods or from nature by } \\
\text { processes such as pressing, refining, grinding, milling, and spray drying }\end{array}$ & $\begin{array}{l}\text { Salt; sugar and molasses; honey and syrup; vegetable oils; butter } \\
\text { and lard; starches extracted from corn and other plants }\end{array}$ \\
\hline 4 & $\begin{array}{l}\text { Ultra-processed } \\
\text { food and drink } \\
\text { products }\end{array}$ & $\begin{array}{l}\text { Formulations of ingredients, mostly of exclusive industrial use, that re- } \\
\text { sult from a series of industrial processes, many requiring sophisticated } \\
\text { equipment and technology. These include the fractioning of whole } \\
\text { foods into substances, chemical modifications of these substances, } \\
\text { assembly of unmodified and modified food substances using industrial } \\
\text { techniques such as extrusion, moulding and pre-frying, frequent } \\
\text { application of additives whose function is to make the final product } \\
\text { palatable or hyper-palatable (cosmetic additives), and sophisticated } \\
\text { packaging, usually with synthetic materials }\end{array}$ & $\begin{array}{l}\text { Carbonated drinks; ice cream, chocolate, confectionery; mass } \\
\text { produced packaged breads and buns; margarines and spreads; } \\
\text { biscuits, pastries, cakes, and cake mixes; breakfast cereals, cereal } \\
\text { and energy bars; energy drinks; milk drinks, fruit yoghurts, and fruit } \\
\text { drinks; meat and chicken extracts and instant sauces; infant formula } \\
\text { milks and other baby products; health and slimming products such } \\
\text { as meal substitutes; many ready to heat products, including pies, } \\
\text { pasta dishes, and pizza; poultry and fish nuggets, sausages, burg- } \\
\text { ers, and hot dogs; and instant soups, noodles, and desserts }\end{array}$ \\
\hline
\end{tabular}

which can lead to overconsumption. ${ }^{19}$ However, wider factors may also encourage consumption. Ultra-processed foods offer convenience for many consumers. Shelf stable products reduce the need for refrigeration or frequent grocery shopping. ${ }^{24}$ Sealed packages can increase perceptions of safety. ${ }^{25}$ Those that are ready-to-eat reduce the time and fuel costs of cooking and the need for adequate kitchen facilities.

Food marketing also influences food preferences, purchasing, and consumption- particularly in children, ${ }^{26}$ and ultra-processed foods are often marketed in ways that appeal specifically to children. ${ }^{23}$ Since ultra-processed foods tend to have longer shelf lives than less processed foods there is less risk of waste for manufacturers and retailers. This allows them to afford very small profit margins on individual sales, but they must sell substantial volume to generate appropriate revenue-hence the need for marketing. Furthermore, increasing global market concentration, where a small number of brands dominate the global market, means that marketing may be the only way that manufacturers of ultra-processed foods can differentiate their products. ${ }^{167}$

Although further work is needed to clarify these potential mechanisms of harm to health from ultra-processed foods, public health action could still be justified in the meantime.

\section{Over-reliance on nutrient reformulation}

One common approach to addressing the concentration of less healthful characteristics in ultra-processed foods is what has been termed nutrients-to-limit reformulation. ${ }^{28}$ This focuses on incentivising the reduction of specific nutrients such as unhealthy fats, free sugars, or sodium in targeted products. For example, the sliding scale design of South Africa's health promotion levy, which taxes drinks based on their sugar concentration, has resulted in reduced sugar concentration of drinks. ${ }^{29}$ Other successful strategies include voluntary salt reformulation targets in the $\mathrm{UK},{ }^{30}$ mandatory calorie labelling in restaurant chains in the US, ${ }^{31}$ and marketing bans for foods not meeting formulation targets in Chile. ${ }^{32}$

Many of these reformulation strategies may also be doing double duty by limiting some of the wider factors driving consumption of ultra-processed foods. For example, Chile's marketing restrictions on foods not meeting formulation targets both reduced children's exposure to marketing of these products ${ }^{33}$ and prompted reformulation. ${ }^{32}$

Despite some success, nutrients-to-limit reformulation is only likely to produce public health benefits in places with minimal growth in the ultra-processed foods market, such as Europe and the US. ${ }^{28}$ Elsewhere, any marginal improvements achieved by reformulation may be outweighed by rapid increases in total consumption of ultra-processed foods. Furthermore, such reformulation can lead to perverse effects with, for example, a focus on reducing unhealthy fats leading to an increase in free sugars. ${ }^{34}$ Similarly, the current focus on reducing free sugars may lead to increases in low calorie sweeteners. If ultra-processing is in itself harmful to health then modifying nutrient content will do nothing to address this problem.

Nutrients-to-limit reformulation reflects a widespread focus of dietary public health policy on nutrients, rather than foods and food practices. However, if ultra-processing drives overconsumption partly through wider, non-biological, mechanisms, intervening in these mechanisms could lead to greater global improvements in health than a focus on the biological harms of individual nutrients. Rather than determining how we can make incremental changes in the nature of ultra-processed foods, global public health nutrition policy should focus further on policies that promote widespread access to convenient, palatable, and affordable minimally processed foods and dishes.

\section{Whole food reformulation}

An alternative to nutrient specific reformulation is whole food reformulation-or development of less processed alternatives. Many ultra-processed foods already have less processed alternatives (eg, canned fruit instead of processed fruit "leathers"; rolled whole oats instead of ultraprocessed breakfast cereals), indicating that this is potentially viable. Given the importance of the food industry to the global economy, agricultural and economic incentives that support development of different products while maintaining profits will be important, not least because employment is an important influence on diet and health.

A key concern around whole food reformulation is affordability. ${ }^{28}$ Currently, less processed alternatives are often more expensive than ultra-processed foods ${ }^{35}$. One potential approach to maintaining affordability is through greater use of fiscal levers. The cost of ultra-processed food and drinks, and their ingredients, can be increased by increasing taxes and decreasing subsidies on these products. 
Similarly, the cost of less processed alternatives, and their ingredients, can be decreased by increasing subsidies and decreasing taxes. Many countries, for example, have introduced consumer facing taxes on sugar sweetened beverages. A recent systematic review found that these are associated with significant reductions in consumption of taxed drinks and non-significant increases in untaxed drinks. ${ }^{36}$ Altering current tax and subsidy structures for food producers and manufacturers could further support whole food reformulation. For example, subsidies on corn production in the US have been implicated in the widespread use of cheap high-fructose corn syrup in ultra-processed foods. $^{37}$

\section{Moving from home prepared to hand prepared} Reducing consumption of ultra-processed foods is now part of national dietary guidance in Brazil and Canada. ${ }^{3839}$ A core stated strategy to achieve this in both cases is greater reliance on home preparation of food. However, a greater focus on "hand prepared" food, irrespective of whether it's prepared at home, may be more realistic.

Evidence shows that greater consumption of home prepared food is associated with improved dietary intake, ${ }^{40}$ but less is known about how to increase food preparation at home. ${ }^{41}$ Most interventions assume a knowledge or skills deficit and focus on cooking demonstrations and classes. However, there are many other reasons why people do not prepare more food at home, including lack of time, poor access to affordable ingredients and adequate kitchen facilities, high costs of cooking fuel, and preferences for ultra-processed foods. ${ }^{25}{ }^{40}$ Furthermore, home food preparation remains highly gendered $^{40}$ and any attempts to increase it may fall disproportionately on women.

An alternative to greater reliance on home food preparation is greater availability of affordable and nutritious hand prepared food-that is, food prepared by hand from less processed ingredients but not necessarily in the home. Affordable and nutritious are important-not all hand prepared food is nutritious ${ }^{42}$ or made from less processed ingredients and hand prepared food needs to be similarly priced to ultra-processed foods.

\section{Strategies to increase consumption of hand prepared food}

Potential strategies to increase availability of affordable, nutritious hand or home prepared food can be considered at the household, community, retail, and national level (table 2). Although many of these strategies focus on increasing the supply of handmade food, they are also likely to help increase the perceived value of this food, thus driving demand.

At the household level, meal kits providing premeasured ingredients and illustrated recipe cards may support home food preparation by reducing the time, energy, and motivation needed to cook and do the associated planning and shopping. The potential of recipe boxes as a dietary public health intervention is largely untested. Boxes in Australia provide contents that could be further improved to maximise healthfulness but are prohibitively expensive for many (AU\$11.65; £6.40, €7.20; \$8 per serving). ${ }^{43}$

"Quick and easy" recipes are often seen as a solution to the reported lack of time for home food preparation. But it may be more effective to increase the amount of predictably available time through maximum working hour mandates, stable employment contracts, and regular working schedules. Better access to affordable ingredients (through tax and subsidy strategies), adequate kitchen facilities (through building codes), and affordable cooking fuel could overcome other known barriers to home food preparation.

Within communities, various meal sharing strategies have been proposed to reduce the individual effort required to access hand prepared food. These include taking turns to prepare meals for large groups in central facilities, and meal sharing services where "spare" portions are offered to neighbours. ${ }^{44}$

Retailers could also offer more nutritious and affordable food. Food vendors are a common source of affordable and convenient handmade food in low and middle income countries, but the food is often of poor nutritional quality. Recent efforts to improve the nutritional quality of street food show some promise. ${ }^{45}$ Supermarkets are an important source of ingredients, but they also sell ultraprocessed foods, and in some places this is their predominant offer. ${ }^{25}$ Supermarkets could be encouraged to move away from ultra-processed foods-for example, by mandatory requirements to report sales of ultra-processed foods as a proportion of all sales. ${ }^{46}$

At the national level, food procurement policies could be used to shape the food served in public sector establishments such as schools, hospitals, and government offices. ${ }^{47}$ These could be focused on favouring hand prepared food over ultraprocessed food, although enforcing this may be challenging in some places.

\begin{tabular}{ll}
\hline \multicolumn{2}{l}{ Table $\mathbf{2}$ | Potential strategies to increase consumption of hand prepared food } \\
\begin{tabular}{ll} 
Mechanism of action & Potential strategy \\
Household & Affordable, nutritious meal kits \\
\hline Decrease time burden of preparing food at home & Maximum working hour mandates \\
\hline Increase household supply of predictable time & Regular working schedules \\
\cline { 2 - 2 } & Stable employment contracts \\
\hline Increase affordability of less processed foods and ingredients & Consumer facing taxes and subsidies \\
\hline Increase access to adequate cooking facilities & Building codes incorporating adequate kitchen facilities \\
\hline Increase affordability of cooking fuel & Fuel price controls \\
\hline Communities & \\
\hline Increase availability of affordable, nutritious hand-prepared food & Community kitchens and meals \\
\cline { 2 - 2 } & Phone based apps to share spare meal portions \\
\hline Retailers & \\
\hline Increase availability of affordable, nutritious hand prepared food & Support use of less processed ingredients by street food vendors \\
\hline National & Mandate reporting of ultra-processed foods sales as a proportion of all sales \\
\hline Increase availability of affordable, nutritious hand prepared food & Food procurement policies \\
\hline
\end{tabular} \\
\hline
\end{tabular}




\section{Synergistic actions}

We have described a range of strategies for rebalancing the availability, affordability, and consumption of ultra-processed foods and less processed alternatives. These recognise both the biological and wider mechanisms of harm of ultra-processed foods and often address both simultaneously. Few of them are novel, indicating that ultra-processed foods do not pose a particularly unique challenge to public health. However, the lens of ultra-processed foods offers an opportunity for reconceptualising the policy problem of poor nutrition in a way that strengthens the imperative to deploy structural strategies, rather than simply continuing with reformulation, education, or motivational strategies. It may also help researchers and policy makers redefine outcomes of interest. Many structural interventions with the potential to improve dietary public health are likely to affect intake of many different foods and nutrients. ${ }^{48}$ Evaluating the impact of these interventions on ultraprocessed food intake is one way to capture these broad effects.

It is unlikely that any single intervention will achieve substantial change. Instead simultaneous action in multiple areas may lead to potentiation of effects. For example, changes to supply and demand cannot be considered independently. Supply side changes in what food is made financially (through fiscal interventions), cognitively (through changes in food marketing), and physically (through changes in what food is displayed in supermarkets) available to consumers will only be economically viable if demand side change leads to consumers placing greater value on hand prepared food. Similarly, the economic influences of changing demand will be felt by food producers only if there are some early supply changes so that consumers have something different to demand.

The global presence of many ultraprocessed foods companies further emphasises the need for coordinated action not just within, but also between, countries. There is a real risk that effective action to reduce ultra-processed foods sales in high income countries leads to efforts to build compensatory growth in poorer nations. The comprehensive action we have proposed can be powerfully supported by global policy actors such as the World Health Organization. Recommendations that support, for example, whole food approaches to reformulation, consideration of community food facilities in urban design, and protection of policy space for strong nutrition policy interventions such as taxes and labelling in trade and investment agreements would create an enabling environment for such action.

Increasing awareness of the health harms of ultra-processed foods provides the opportunity for a shift in global dietary public health policy away from a strict focus on individual nutrients and dietary behaviours, towards the wider social, economic, commercial, and political drivers of the overproduction and overconsumption of some types of food over others. This approach should also ensure that the most vulnerable and food insecure also benefit. Coordinated action at local, national, and transnational levels will be required to seize these opportunities and equitably improve dietary public health.

Contributors and sources: JA leads publicly and charitably funded research on population level influences on, and interventions with the potential to improve, dietary public health. KH leads a public health research to policy unit focused on "best buys" and priority setting to improve health outcomes. $\mathrm{J}-\mathrm{CM}$ is trained in anthropology, public health, and nutrition. He contributed to the development of the Nova system and has applied it to monitor consumption of ultra-processed food in Canada and globally and assess its impact on diet quality and human health. He also works on the commercial determinants of health and public policies for healthy and sustainable food systems. AMT leads a programme of research on nutrition policy; she has published widely on policy analyses and the political economy of increasing consideration of nutrition in food system policy making. The article is based on the authors' collective professional experience and review of material in the public domain. JA led the drafting of the article and all authors contributed to developing the arguments, researching the literature, providing comments and edits on earlier drafts, and approved the final version. JA is guarantor.

Competing interests: We have read and understood BMJ policy on declaration of interests and have the following interests to declare: JA is funded by the Centre for Diet and Activity Research (CEDAR). CEDAR is a UK Clinical Research Collaboration Public Health Research Centre of Excellence, with funding from the British Heart Foundation, Cancer Research UK, Economic and Social Research Council, Medical Research Council (MRC), National Institute of Health Research (NIHR) and Wellcome Trust. JA has been a member of panels advising governmental and charitable organisations. KH has been a member of several ministerial task teams and national health committees and is a fellow of the Academy of Science of South Africa (ASSAf). J-CM helped develop the Nova system and has worked as a consultant for the Food and Agriculture Organization of the United Nations and PAHO. He is a member of the WHO Nutrition Policy sub-Group of the Nutrition Guidance Advisory Group, which is tasked with developing formal policy guidance on nutrition for all member states.

Provenance and peer review: Commissioned; externally peer reviewed.

This article is one of a series commissioned by The $B M J$. Open access fees for the series were funded by Swiss Re, which had no input into the commissioning or peer review of the articles. The BMJ thanks the series advisers, Nita Forouhi, Dariush Mozaffarian, and Anna Lartey for valuable advice and guiding selection of topics in the series.

Jean Adams, senior university lecturer ${ }^{1}$ Karen Hofman, director ${ }^{2}$

Jean-Claude Moubarac, assistant professor ${ }^{3}$

Anne Marie Thow, associate professor ${ }^{4}$

${ }^{1}$ Centre for Diet and Activity Research, MRC Epidemiology Unit, University of Cambridge, Cambridge, UK

${ }^{2}$ South Africa MRC/Wits Centre for Health Economics and Decision Science, University of the Witwatersrand, Johannesburg, South Africa

${ }^{3}$ Department of Nutrition, Faculty of Medicine, University of Montreal, Montreal, Canada

${ }^{4}$ Menzies Centre for Health Policy, School of Public Health, University of Sydney, Sydney Australia

Correspondence to: J Adams

Jma79@medschl.cam.ac.uk

\section{(c) 1 (1)}

This is an Open Access article distributed in accordance with the Creative Commons Attribution Non Commercial (CC BY-NC 4.0) license, which permits others to distribute, remix, adapt, build upon this work non-commercially, and license their derivative works on different terms, provided the original work is properly cited and the use is non-commercial. See: http://creativecommons.org/ licenses/by-nc/4.0/.

\section{Check for updates}

1 Laudan R. A plea for culinary modernism: why we should love new, fast, processed food Gastronomica 2001;1:36-44. doi:10.1525 gf. 2001.1.1.36

2 Pulker CE, Scott JA, Pollard CM. Ultra-processed family foods in Australia: nutrition claims, health claims and marketing techniques. Public Health Nutr 2018;21:38-48. doi:10.1017/ S1368980017001148

3 Gamboa-Gamboa T, Blanco-Metzler A, Vandevijvere S, Ramirez-Zea M, Kroker-Lobos MF. Nutritional content according to the presence of front of package marketing strategies: the case of ultraprocessed snack food products purchased in Costa Rica. Nutrients 2019;11:2738. doi:10.3390/ nu11112738

4 Poti J, Mendez M, Ng SW, Popkin B. Ultra-processed and ready-to-eat food and beverage purchases differ by race, education, and income in a longitudinal US study. FASEB J 2015;29(Supplement).

5 Moubarac JC, Claro RM, Baraldi LG, et al. International differences in cost and consumption of readyto-consume food and drink products: United Kingdom and Brazil, 2008-2009. Glob Public Health 2013;8:845-56. doi:10.1080/17441692.20 13.796401

6 Moubarac J-C, Batal M, Martins APB, et al. Processed and ultra-processed food products: consumption trends in Canada from 1938 to 2011. Can J Diet Pract Res 2014;75:15-21. doi:10.3148/75.1.2014.15

7 Monteiro CA, Cannon G, Levy RB, et al. Ultraprocessed foods: what they are and how to identify them. Public Health Nutr 2019:22:936-41. doi:10.1017/S1368980018003762

8 Gibney MJ, Forde CG, Mullally D, Gibney ER. Ultraprocessed foods in human health: a critical appraisal. Am J Clin Nutr 2017;106:717-24. doi:10.3945/ ajcn.117.160440

9 Monteiro CA, Cannon G, Moubarac JC, Levy RB, Louzada MLC, Jaime PC. Ultra-processing. An odd ‘appraisal'. Public Health Nutr 2018;21:497-501. doi:10.1017/S1368980017003287 
10 Moubarac J-C, Parra DC, Cannon G, Monteiro CA. Food classification systems based on food processing: significance and implications for policies and actions: a systematic literature review and assessment. Curr Obes Rep 2014;3:256-72. doi:10.1007/s13679-014-0092-0

11 Vandevijvere S, Jaacks LM, Monteiro CA, et al. Global trends in ultraprocessed food and drink product sales and their association with adult body mass index trajectories. Obes Rev 2019;20(Suppl 2):10-9. doi:10.1111/obr.12860

12 Djupegot IL, Nenseth CB, Bere E, et al. The association between time scarcity, sociodemographic correlates and consumption of ultra-processed foods among parents in Norway: a cross-sectional study. BMC Public Health 2017;17:447. doi:10.1186/ s12889-017-4408-3

13 Moubarac J-C, Martins APB, Claro RM, Levy RB, Cannon G, Monteiro CA, Evidence from Canada. Consumption of ultra-processed foods and likely impact on human health. Public Health Nutr 2013;16:2240-8. doi:10.1017/ S1368980012005009

14 Schnabel L, Kesse-Guyot E, Allès B, et al. Association between ultraprocessed food consumption and risk of mortality among middle-aged adults in France. JAMA Intern Med 2019;179:490-8. doi:10.1001/ jamainternmed.2018.7289

15 Simões BDS, Barreto SM, Molina MDCB, et al. Consumption of ultra-processed foods and socioeconomic position: a cross-sectional analysis of the Brazilian Longitudinal Study of Adult Health (ELSA-Brasil). Cad Saude Publica 2018;34:e00019717. doi:10.1590/0102 $311 \times 00019717$

16 Baker P, Friel S. Food systems transformations, ultraprocessed food markets and the nutrition transition in Asia. Global Health 2016;12:80. doi:10.1186/ s12992-016-0223-3

17 Coca-Cola statistics and facts. Market.us, 17 Jan 2020. https://market.us/statistics/food-and beverage-companies/coca-cola-company/.

18 Stafford L. Coca-Cola to spend $\$ 30$ billion to grow globally. Atlanta Journal-Constitution 2012 Sep 9. https://www.ajc.com/business/coca-cola-spendbillion-grow-globally/w9gISxxVOdkJOQAZrnUOdM /\#: :text=By\%20the\%20year\%202020\%2C\%20 more,hopes\%20they'll\%20be\%20thirsty

19 Hall KD, Ayuketah A, Brychta R, et al. Ultraprocessed diets cause excess calorie intake and weight gain: an inpatient randomized controlled trial of ad libitum food intake. Cell Metab 2019;30:67-77.e3. doi:10.1016/j. cmet.2019.05.008

20 Fiolet T, Srour B, Sellem L, et al. Consumption of ultra-processed foods and cancer risk: results from NutriNet-Santé prospective cohort. BMJ 2018;360:k322. doi:10.1136/bmj. k32210.1136/bmj.k322

21 Srour B, Fezeu LK, Kesse-Guyot E, et al. Ultraprocessed food intake and risk of cardiovascular disease: prospective cohort study (NutriNet-Santé). BM/ 2019;365:l1451. doi:10.1136/bmj.l1451
22 Luiten CM, Steenhuis IHM, Eyles H, Ni Mhurchu C, Waterlander WE. Ultra-processed foods have the worst nutrient profile, yet they are the most available packaged products in a sample of New Zealand supermarkets. Public Health Nutr 2016;19:530-8. doi:10.1017/S1368980015002177

23 Monteiro C, Cannon G, Lawrence M, Louzada M, Machado P. Ultra-processed foods, diet quality, and health using the NOVA classification system. FAO, 2019.

24 Battersby J, Peyton S. The geography of supermarkets in Cape Town: supermarket expansion and food access. Urban Forum 2014:25:153-64 doi:10.1007/s12132-014-9217-5

25 Hunter-Adams J, Battersby J, Oni T. Food insecurity in relation to obesity in peri-urban Cape Town, South Africa: Implications for diet-related noncommunicable disease. Appetite 2019;137:244-9. doi:10.1016/j.appet.2019.03.012

26 Cairns G, Angus K, Hastings G, Caraher M. Systematic reviews of the evidence on the nature, extent and effects of food marketing to children. A retrospective summary. Appetite 2013;62:209-15. doi:10.1016/j. appet.2012.04.017

27 Vidler A-C, Stoneham M, Edmunds M, Sartori A. The illusion of choice: an exploratory study looking at the top 10 food companies in Australia and their brand connections. Aust N Z J Public Health 2018;42:51922. doi:10.1111/1753-6405.12828

28 Scrinis G, Monteiro CA. Ultra-processed foods and the limits of product reformulation. Public Health Nutr 2018;21:247-52. doi:10.1017/ S1368980017001392

29 Stacey N, Mudara C, Ng SW, van Walbeek C, Hofman $\mathrm{K}$, Edoka I. Sugar-based beverage taxes and beverage prices: evidence from South Africa's health promotion levy. Soc Sci Med 2019;238:112465. doi:10.1016/j.socscimed.2019.112465

30 He FJ, Brinsden HC, MacGregor GA. Salt reduction in the United Kingdom: a successful experiment in public health. J Hum Hypertens 2014;28:345-52. doi:10.1038/jhh.2013.105

31 Zlatevska N, Neumann N, Dubelaar C. Mandatory calorie disclosure: a comprehensive analysis of its effect on consumers and retailers. J Retailing 2018;94:89-101. doi:10.1016/j. jretai.2017.09.007

32 Taillie LS, Reyes M, Colchero MA, Popkin B, Corvalán C. An evaluation of Chile's law of food labeling and advertising on sugar-sweetened beverage purchases from 2015 to 2017: a before-and-after study. PLoS Med 2020;17:e1003015. doi:10.1371/journal. pmed.1003015

33 Dillman Carpentier FR, Correa T, Reyes M, Taillie LS. Evaluating the impact of Chile's marketing regulation of unhealthy foods and beverages: pre-school and adolescent children's changes in exposure to food advertising on television. Public Health Nutr 2020;23:747-55. doi:10.1017/ S1368980019003355

34 Nguyen PK, Lin S, Heidenreich P. A systematic comparison of sugar content in low-fat vs regular versions of food. Nutr Diabetes 2016;6:e193. doi:10.1038/nutd.2015.43
35 Jones NRV, Conklin Al, Suhrcke M, Monsivais P. The growing price gap between more and less healthy foods: analysis of a novel longitudinal UK dataset. PLoS One 2014;9:e109343. doi:10.1371/journal. pone.0109343

36 Teng AM, Jones AC, Mizdrak A, Signal L, Genç M, Wilson N. Impact of sugar-sweetened beverage taxes on purchases and dietary intake: systematic review and meta-analysis. Obes Rev 2019;20:1187-204. doi:10.1111/obr.12868

37 Nestle M. Food politics: how the food industry influences nutrition and health. University of California Press, 2013.

38 Monteiro CA, Cannon G, Moubarac JC, et al. Dietary guidelines to nourish humanity and the planet in the twenty-first century. A blueprint from Brazil. Public Health Nutr 2015;18:2311-22. doi:10.1017/ S1368980015002165

39 Government of Canada. Canada's food guide 2020. https://food-guide.canada.ca/en/.

40 Mills S, White M, Brown H, et al. Health and social determinants and outcomes of home cooking: a systematic review of observational studies. Appetite 2017;111:116-34. doi:10.1016/j. appet.2016.12.022

41 Reicks M, Kocher M, Reeder J. Impact of cooking and home food preparation interventions among adults: a systematic review (2011-2016). J Nutr Educ Behav 2018;50:148-172.e1. doi:10.1016/j. ineb.2017.08.004

42 Mills SDH, Wolfson JA, Wrieden WL, Brown H, White M, Adams J. Perceptions of 'home cooking': a qualitative analysis from the United Kingdom and United States. Nutrients 2020;12:198. doi:10.3390/ nu12010198

43 Gibson AA, Partridge SR. Nutritional qualities of commercial meal kit subscription services in Australia. Nutrients 2019;11:E2679. doi:10.3390/nu11112679

44 Bowen S, Brenton J, Elliott S. Pressure cooker: why home cooking won't solve our problems and what we can do about it. Oxford University Press, 2019.

45 Hill J, Mchiza Z, Puoane T, Steyn NP. The development of an evidence-based street food vending model within a socioecological framework: a guide for African countries. PLoS One 2019;14:e0223535. doi:10.1371/journal.pone.0223535

46 Pulker CE, Trapp GSA, Scott JA, Pollard CM. The nature and quality of Australian supermarkets' policies that can impact public health nutrition, and evidence of their practical application: a cross-sectiona study. Nutrients 2019;11:E853. doi:10.3390/ nu11040853

47 Moubarac J. Ultra-processed food and drink products in Latin America: Trends, impact on obesity, policy implications. PAHO, 2015.

48 Penney T, Adams J, Briggs A, et al. Theorising how the UK soft drinks industry levy could impact population level diet and health: development of a multi-sectoral systems map. International Society for Behavioural Nutrition and Physical Activity, 2017.

Cite this as: BMJ 2020;369:m2391

http://dx.doi.org/10.1136/bmj.m2391 